\title{
THOMAS PEEL DUNHILL, THE FORGOTTEN MAN OF THYROID SURGERY
}

by

\author{
I. D. A. VELLAR*
}

THE MODERN surgeon approaches the surgery of thyrotoxicosis with confidence, the confidence derived from the excellence of modern anaesthesia, the euthyroid state of the patient and the knowledge that blood transfusion, antibiotics and the specific management of the occasional crisis are always available to extricate the patient from any of these complications. Though full of confidence in his own and others' abilities, he usually matches this by a profound ignorance of the contribution of the thyroid pioneers whose activities at the turn of the century helped to lay the foundation for the safe management of the thyrotoxic. One of these pioneers was an Australian, Thomas Peel Dunhill (fig. 1), whose contributions to thyroid surgery have been almost entirely forgotten. To understand fully the role of Dunhill, it is important to look at the position of thyroid surgery and in particular, the surgery of toxic goitre at the turn of the nineteenth century and in the first two decades of the twentieth century. It will then be possible to appreciate more fully the achievements of these thyroid pioneers, who enabled the mortality of the surgery of toxic goitre to be reduced from 30-50 per cent (it was 30 per cent at St. Thomas's Hospital, London, as recently as 1910) to a minute fraction of one per cent today.

The early history of the surgery of the thyroid gland may be traced in Halsted's painstaking compilations included in his article. 'The operative story of goitrethe author's operation' in the Johns Hopkins Hospital Reports, 1920. ${ }^{1}$ However, the recognition of goitre goes back many thousands of years. The Arthorva Veda, an ancient Hindu collection of incantations dating from 2000 B.C., contains extensive forms of exorcisms for goitre. In more recent times, Julius Caesar remarked at the frequent occurrence of a big neck as one of the characteristics of the Gauls. Juvenal, the Roman poet, indicated the frequency of goitre when he wrote: 'Quis tumidum guttur miratur in Alpibus?' ('Who wonders at goitre in the Alps?') 'Goitre' is derived from the Latin 'guttur', the throat, and Fabricius ab Aquapendente of Padua was probably the first to employ this term when he described sufferers from goitre as 'gutturosi'. In the sixteenth to eighteenth centuries, it was also called 'struma' and often confused with enlargement of the cervical lymph nodes. That goitre was definitely associated with enlargement of the thyroid gland does not appear to have gained general recognition until the eighteenth century. Against this background Halsted's researches, based partly on his own work and that of the German medical historians Mandt and Günther, showed that some 100 operations were performed on the thyroid gland between 1596 and 1861 . The majority of these operations were

*Department of Surgery, St. Vincent's Hospital, Fitzroy, Victoria 3065, Australia.

Medical History, 1974, vol. 18. 


\section{Thomas Peel Dunhill, the Forgotten Man of Thyroid Surgery}

performed before the introduction of ether to medicine in 1846. Though the operations claimed to have been performed in the sixteenth and seventeenth centuries are shrouded in doubt and ambiguity, it appears fairly certain that Pierre Joseph Desault excised a large adenoma of the thyroid in 1791. The patient, a young woman aged twenty-eight, recovered. Desault's second attempt at thyroidectomy ended disastrously, the patient dying from uncontrollable haemorrhage. As in other branches of surgery at that time, control of haemorrhage and the prevention of infection were proving formidable obstacles for the surgeons. Tissues were grasped by hooks, pincers, or with the fingers. Ligatures were expected to slough off as the wound healed with the inevitable accompaniment of laudable pus (and many a time secondary haemorrhage as well). The intrepid Baron Dupuytren in the early part of the nineteenth century removed a large adenoma of the thyroid. Though technically successful, the patient died of respiratory failure thirty-five hours later. This case was reported in 1817. Probably the greatest achievements of the early thyroid surgeons belong to J. A. W. Hedenus of Dresden. He excised part of the thyroid with success in six patients. Like most of the operations performed at that time, he operated to relieve pressure symptoms resulting from the enlarging goitre. Other isolated successful operations for non-toxic goitre were reported from Britain, Italy and America. However, the general attitude towards operating on the thyroid at that time was forcefully stated by Robert Liston when he wrote: 'You could not cut the thyroid gland out of the living body in its sound condition without risking the death of the patient from haemorrhage. It is a proceeding by no means to be thought of'. ${ }^{2}$ Samuel D. Gross was even more forceful in his views. He asked: 'In a word, can the thyroid gland when in a state of enlargement, be removed with a reasonable hope of saving the patient? Experience emphatically answers no'. ${ }^{3}$ The twin scourges of sepsis and haemorrhage actually forced the French Academy of Medicine in 1850 to prohibit operations on goitre. The advent of general anaesthesia in 1846, the introduction of Listerian principles of antisepsis and asepsis in the 1870-1890 period, which were adopted at first by the surgeons of the German school, and the development of satisfactory haemostats, all helped to eliminate the 'smash and grab' school of surgery and of course substantially reduced surgical mortality. Thyroid surgery particularly benefited from these advances and in the period 1861-1883 nearly 500 operations on the thyroid gland were reported. This was the period dominated by Theodor Billroth and his school and marked the debut of Theodor Kocher to thyroid surgery. Switzerland, having such a large number of patients with goitre, naturally became the centre of thyroid surgery. This interest was initiated and fostered by Billroth when he held the Chair of Surgery in Zurich during the period 1860-1867. Professor A. Lücke carried on the work at Berne and he of course was succeeded by Kocher who held the Chair of Surgery at Berne from 1872-1911. During his tenure of the Chair of Surgery at Zurich, Billroth performed twenty major operations on the thyroid. Eight of these patients died, a mortality of $\mathbf{4 0}$ per cent. Sepsis accounted for the majority of the deaths. By the time Billroth had established himself in Vienna, Lister's antiseptic methods had been adopted by the German-Austrian-Swiss school of surgery. Once more, but now with greater confidence, Theodor Billroth directed his talents towards the problems of goitre surgery. By 1882 , he had reduced his mortality to 8 per cent. 


\section{D. A. Vellar}

In forty-eight major operations on the thyroid, including twenty-two total extirpations, Billroth injured the recurrent laryngeal nerve some thirteen times. Eight of the twenty-two total extirpations developed tetany. Two of these patients died. This improvement in results was achieved with a somewhat crude technique. Billroth did not dissect out and isolate the superior and inferior thyroid arteries and ligate them as a definite step in excision of the thyroid. He tied all vessels en masse as they were encountered. It was this technique almost certainly that caused the recurrent laryngeal nerve to be caught and damaged or cut with the inferior thyroid artery. The high proportion of cases who had the thyroid totally removed and developed tetany, naturally provoked intense interest and discussion amongst Billroth and his disciples. Anton Wölfler, one of Billroth's assistants, postulated that the tetany resulted from a disorder of the cerebral circulation following removal of the thyroid gland. Billroth however, incriminated division of the numerous nerves of the thyroid gland and believed that tetany only occurred in individuals who were predisposed to nervous affections! One has to remember that Sandström had just described the parathyroid glands (1880) and that physiological knowledge of thyroid and parathyroid function was nil. It is indeed ironical that the improvements in operating technique and haemostasis allied with Listerian antisepsis and asepsis, enabled total extirpation of the thyroid to be carried out successfully and thus unveiled postoperative myxoedema and tetany. Billroth, adopting a relatively crude technique of thyroidectomy, had trouble with tetany and recurrent laryngeal nerve damage. Kocher, the meticulous dissector, was plagued by postoperative myxoedema, but the recurrent laryngeal nerve was safe in his hands. Historically, the honour of the first successful total thyroidectomy belongs to Paul Sick. He achieved this in 1867. The patient was a ten-year-old boy and Sick operated to relieve increasingly severe dyspnoea. Sick noted in his follow-up examination that the boy 'formerly joyous and lively, he is now silent, quiet and dull'.4 He speculated that some alteration in the blood might have impaired the nutrition of the brain. Sick of course was actually describing post-operative myxoedema. However, he failed to correlate removal of the thyroid with the changes which he described. Five years after Sick's successful operation, Theodor Kocher obtained the Chair of Surgery at Berne at the age of thirty-one years. Kocher succeeded Lücke who had initiated goitre surgery at Berne in 1872. By 1874, he had performed two total excisions of the thyroid successfully. One of these was on an eleven-year-old girl. Kocher noted: 'According to the report of the physician she enjoyed unclouded health during the past two weeks after her return home, but latterly a remarkable change in the behaviour of the child has taken place. She has become peevish and dull and will not work except under compulsion, whereas formerly she was a spirited and joyous creature. We shall learn from the further progress of the case whether there is any relation between the extirpatio strumae and the altered mental condition.'5 These were prophetic words because in 1883 Kocher published his famous paper detailing results of total thyroidectomy and describing a standard approach for thyroid lobectomy. ${ }^{\circ}$ By now, Kocher had performed thirty-four total excisions of the thyroid. Eighteen of these returned for follow-up examination. Sixteen showed hypothyroidism. These are described fully. Kocher noted the similarity between cretinism and the postoperative state he now 


\section{Thomas Peel Dunhill, the Forgotten Man of Thyroid Surgery}

designated 'cachexia strumi priva'. Without any precise knowledge of thyroid function, Kocher speculated as to the cause of the cachexia strumi priva and the anaemia which was such a prominent feature of the disorder. Softening of the trachea was incriminated as well as some disorder of the cerebral circulation. Kocher states: 'We believe, therefore, that the symptoms which condition the picture of idiocy are probably determined by the disturbance of the cerebral circulation, while the cachexia is to be explained by the influence upon breathing, upon the supply of oxygen in so far at least as it may not be ascribed to the cutting out of that function of the thyroid gland which serves in the formation of the blood'. Only one of the eighteen cases which returned for follow-up examination showed tetany and this was regarded by Kocher as a manifestation of the intense cerebral disturbance. Although these observations of Kocher contained in the famous article entitled 'Ueber Kropf Extirpation' were eventually to lead him to the Nobel Prize for medicine in 1909 , he was actually antedated by J. L. Reverdin of Geneva. In 1882 Reverdin reported fourteen total excisions of the thyroid gland. He noted that some months after the operation the patients developed a feebleness, pallor and heaviness. The face became swollen and resembled very closely cretinoid facies. Reverdin called the condition 'myxedeme operatoire'.?

The threats of sepsis, haemorrhage and damage to the recurrent laryngeal nerve had now given way to post-operative tetany and cachexia strumi priva. It was these complications that caused Kocher to abandon almost completely total thyroidectomy (he reserved this for certain malignant goitres) and to concentrate on removal of one lobe only. This single lobectomy proved to be the basis of all Kocher's surgery for goitre after 1883. Towards the end of his surgical career, he still attacked only one lobe but now left the posterior part of the lobe behind. By 1883 the Swiss surgeons, in particular Reverdin and Kocher, had become acquainted with some of the English literature pertaining to the thyroid, in particular a paper read by William Withey Gull in 1873 to the Clinical Society of London. This paper was titled 'On a cretinoid state supervening in adult life in women'.8 ${ }^{8}$ Gull pointed out many similarities between this condition (now designated myxoedema) and sporadic cretinism. The actual term 'myxoedema' was first used by William Ord in 1877. Ord coined this term to describe the 'mucous dropsy' of the skin. He was able to perform a post-mortem examination on a patient suffering from severe thyroid deficiency, noting a markedly diminished thyroid gland and the appearance of a gelatinous or mucinoid substance in the subcutaneous tissue, thereby giving the disease entity its name. It was this paper that suggested to Reverdin the term 'myxedeme operatoire'. In 1883 Sir Felix Semon after closely studying the contributions of Kocher and Reverdin (Semon spoke German fluently), stated that cretinism, myxoedema and cachexia strumi priva were closely allied conditions having in common either absence or complete degeneration of the thyroid gland. This hypothesis was proved experimentally by Victor Horsley when he removed the thyroid gland in monkeys, producing a state identical to myxoedema in the human. The role played by the lack of thyroid secretion in the production of myxoedema had to await the isolation of thyroxine by Kendall in 1914.9 Having shown that excision of the thyroid gland produced myxoedema and having noted the resemblance of 'myxoedema operatoire' to sporadic cretinism, it appeared logical 


\section{D. A. Vellar}

to clinicians to try substitution therapy in these disorders. Moritz Schiff claimed that an animal could be safeguarded against some of the effects of thyroid deprivation by transplantation of the thyroid from another animal of the same species. The effect of this procedure was solely due to the thyroid secretion contained in the thyroid homograft and not to the graft resuming function. This claim of Schiff impressed Horsley who stated in 1890: 'It seems to me that these observations of Professor Schiff and Dr. von Eiselsberg are of especial value as they suggest to my mind that possibly myxoedema may be treated with success by transplanting thyroid tissue into the patient'. ${ }^{10}$ The work of George Redmayne Murray, Hector MacKenzie and Fox made this unnecessary. In 1891, Murray treated myxoedema successfully by injection of an extract made from sheep's thyroid. ${ }^{11}$ One year later MacKenzie showed that feeding of fresh thyroid glands was equally efficacious ${ }^{12}$ and finally Fox in 1892 described how the clinical features of myxoedema could be completely reversed by taking thyroid extract by mouth. ${ }^{13}$

The serious side-effects of total thyroidectomy (cachexia strumi priva and tetany) had a profound effect on many surgeons. Billroth's assistants were able to study these conditions closely. One of his assistants was Johann von Mikulicz-Radecki. After being an assistant to Billroth in Vienna for some years Mikulicz became Professor of Surgery at Cracow. In 1886 he wrote: 'I refer to the general and local disturbances-tetany, cachexia strumi priva and paralysis of the muscles of the laryn $\mathrm{x}$ - which follow strumectomy and which together demand either an essential curtailing of the indications for operation or a modification of the operative method'.14 Although Mikulicz had no accurate idea of the function of the thyroid and probably had taken no notice of the parathyroids (he subscribed to Billroth's theory that both tetany and cachexia strumi priva were somehow due to operative interference with nerves in the vicinity of the thyroid), he realized correctly that excision of a lobe was never followed by tetany or cachexia. He also appreciated that if the dissection spared the region of the recurrent laryngeal nerve, then paralysis of the vocal cord would be eliminated. He achieved this by leaving thyroid tissue behind in the vicinity of the inferior thyroid artery, thereby protecting the recurrent laryngeal nerve (and incidentally and unwittingly), the parathyroids. Although Mikulicz himself usually removed one lobe almost entirely and partially resected the second lobe, in one case he performed a bilateral partial resection, leaving part of the posterior aspects of both lobes behind. This procedure forms the basis for the modern partial thyroidectomy operation. It was never adopted by Kocher who remained content to remove one lobe of the thyroid only, after dissecting and ligating the superior and inferior thyroid arteries. The only change in Kocher's technique was his adoption of the collar incision advocated by Boeckel and the employment of local anaesthesia almost exclusively after 1896. The employment of local anaesthesia was precipitated by a death under chloroform anaesthesia which Kocher experienced in 1895. By 1900, Kocher's mortality for non-toxic goitre was less than one per cent and in 1907 he had amassed 3,333 cases of non-toxic goitre with a mortality of 0.3 per cent. All of these cases had a single lobectomy. By the end of the nineteenth century Kocher had evolved a safe technique for all non-toxic goitre and thyroid extract was widely used to treat myxoedema, post-operative hypothyroidism and cretinism. Tetany still 


\section{Thomas Peel Dunhill, the Forgotten Man of Thyroid Surgery}

remained an enigma. Sandström in 1880 was the first to describe the parathyroid glands as anatomic entities, ${ }^{15}$ although both Remak in 1851 and Rudolf Virchow in 1864 briefly mentioned them. Sandström thought that the parathyroids represented undeveloped embryonic thyroid tissue. This view bedevilled medical thinking for many years for though Gley in 1891 in a series of communications before the Société de Biologie in Paris presented his evidence that thyroidectomy per se did not produce fatal tetany unless the parathyroid glands were also removed, he still considered that the parathyroids represented embryonic thyroid tissue. ${ }^{16}$ In goitre surgery it was well recognized that total ablation of the thyroid gland led to tetany in a number of cases. This led to confusion as many investigators still blamed tetany on thyroid deprivation and tried unsuccessfully to treat it with thyroid extract. It was left to two Italian physiologists, Vassale and Generali, to prove by a series of convincing experiments that it was loss of parathyroid function that caused tetany. ${ }^{17}$ They removed the parathyroids but left the thyroid intact and showed that the experimental animal developed tetany. Conversely, they removed all thyroid but left one of the parathyroids in situ and showed that tetany did not develop. They concluded that parathyroids were not thyroid rests and that they had a special metabolic function separate from the thyroid. MacCallum then showed in 1911-1913 that the hyperexcitability of the nervous system, the hallmark of tetany, resulted from calcium lack in the blood and that the manifestations of tetany were reversed by giving calcium. ${ }^{18}$ Analytical methods at that time were relatively crude and it was sometimes difficult to detect the rather minimal alterations in the calcium levels which were able to produce tetany in experimental animals

As the nineteenth century drew to a close, the figure of Kocher stood like a colossus over the field of goitre surgery. His experience with the surgery of non-toxic goitre was truly phenomenal and his mortality and morbidity exceedingly low. However, he confined himself mainly to a single lobectomy performed through a collar incision under local anaesthesia, utilizing a mid-line split of the strap muscles. Preliminary extracapsular ligature of both superior and inferior thyroid arteries preceded removal of the lobe. At this time, the importance of the parathyroid glands was just beginning to be appreciated by surgeons and the physicians had a potent cure for myxoedema.

In contrast to these advances, the management of thyrotoxicosis or Graves' Disease, was far from satisfactory. Caleb Hillier Parry, a physician in Bath, first described the condition of exophthalmic goitre in 1786 . He briefly reported this condition in his Elements of Pathology and Therapeutics in 1815. A fuller account of exophthalmic goitre is given in an article entitled 'Enlargement of the thyroid gland in connection with enlargement or palpitation of the heart' published posthumously in 1825. ${ }^{19}$ Robert James Graves, in 1835, ${ }^{20}$ and Carl Adolf von Basedow, in 1840, ${ }^{21}$ gave further descriptions associating goitre, palpitation, exophthalmos, emaciation and extreme nervousness. Though the clinical description and recognition of this disease became well established, controversy raged as to the causation of the exophthalmic goitre and its management. Early observers such as Parry and Graves, thought that the heart was the primary cause of the disease. Tillaux, about 1880 , advanced the compression theory, that the symptoms of exophthalmic goitre were due to pressure of the enlarged thyroid gland on related nerves and blood vessels. 


\section{D. A. Vellar}

Jaboulay and Jonnesco incriminated disordered sympathetic activity and advocated removal of the cervical sympathetic chain and ganglia as the definitive step for the cure of exophthalmic goitre. ${ }^{22}$ Others claimed that it was in the parathyroid glands and the thymus that the cause of the disease was to be found. As late as the early twentieth century, workers such as McCarrison still obstinately adhered to a psychic, nutritional and infectious cause of Graves' Disease. ${ }^{23}$ The dominance of the focus of infection as the source of all ills, coupled with the influence of Arbuthnot Lane in incriminating chronic intestinal stasis as the aetiology of such diverse ailments as Graves' Disease, tuberculosis, rheumatoid arthritis and tic doloureux, often led to somewhat unorthodox management of these conditions. McCarrison, in his book The Thyroid Gland quotes the following management of a case of Graves' Disease: ${ }^{24}$ 'Roentgen ray examination by Dr. Jordan revealed the presence of a greatly dilated stomach with pyloric spasm, an elongated duodenum and a state of chronic irritation of the colon resulting in unduly rapid emptying of its contents'. Arbuthnot Lane performed a gastro-jejunostomy, appendicectomy and freed the pelvic colon as the definitive management of this patient's thyrotoxicosis. Within ten months, it was claimed that the patient lost most of her toxic symptoms, although from the description given she was fortunate to have survived a period of severe thyroid crisis as a result of abdominal intervention. Her amelioration was almost certainly due to a spontaneous remission. From this one case, McCarrison concluded that Graves' Disease was due to 'alimentary toxaemia'.

More enlightened observers of course incriminated the thyroid gland itself. As most of the cases of exophthalmic goitre were associated with enlargement of the thyroid, it was natural that the thyroid gland itself should be blamed for the condition. This theory was expounded even before any precise knowledge of thyroid function was available. Indeed, several surgeons such as Tillaux (1880), Rehn (1880) and Mikulicz (1885) more or less accidentally discovered that thyrotoxicosis could be cured by operating on the thyroid gland. It seems that the indication for surgery in each case was respiratory difficulty. Each surgeon was agreeably surprised that the symptoms of thyrotoxicosis diminished greatly or even disappeared after the operation. These represent the earliest recorded surgical attacks on exophthalmic goitre. It is of interest that Mikulicz performed a double resection of the thyroid to cure the thyrotoxicosis, an operation which had to wait for some fifty years before being accepted as the standard technique for the cure of toxic goitre. This delay was certainly due to the dominant influence of Kocher and the inherent dangers of surgery in ill-prepared patients who were often in advanced stages of cardiac failure and emaciation. Theodor Kocher, as has been noted, concentrated on a single lobectomy for the management of both toxic and non-toxic goitres. Between 1884 and 1887 he had operated on five cases of 'Basedow's Disease', as he called it, with one death. By 1907, although he had operated on 3,333 cases of non-toxic goitre with a mortality of 0.3 per cent, he had performed only 200 operations on toxic goitre with a mortality of 4.5 per cent. His definitive management at that time was a lobectomy combined with ligation of the opposite superior thyroid artery. If the thyrotoxicosis was marked, he performed preliminary ligation of one or both superior thyroid vessels before excising one lobe, and states: ${ }^{25}$ 'Even without excising the gland 


\section{Thomas Peel Dunhill, the Forgotten Man of Thyroid Surgery}

we can get very good results in Basedow's Disease by simple ligature of three arteries'. Furthermore, Kocher in his textbook of surgery, 1911, still wrote that: 'Excision should not be undertaken when the disease is advanced, i.e. when the pulse, besides being rapid is also small and irregular, or when the heart is dilated and oedema is present. If there is severe thyro-intoxication, the slightest excitement causing acceleration of the heart's action (180 beats or more per minute) with an increase in the dilatation, it is advisable to begin by ligating one or possibly two arteries and to postpone the excision until the patient's condition shows distinct improvement' ${ }^{26}$

What was the rationale for operating on the thyroid gland in Graves' Disease? P. J. Moëbius in 1886 postulated that disordered function of the thyroid was the raison d'être of Graves' Disease and W. S. Greenfield in 1893 provided histological evidence to support this contention when he was one of the first to describe the typical hyperplasia seen in the thyroid gland in thyrotoxicosis. ${ }^{27}$ Kocher, very early in his career, agreed with Moëbius that the thyroid was primarily at fault in Graves' Disease and that the surgical attack should therefore be directed at the thyroid both by lobectomy and ligature of vessels. Kocher of course was under the misapprehension that ligature of the thyroid arteries was sufficient to interfere with the function of the gland and consequently mitigate the effects of the thyro-intoxication. The importance of a direct surgical attack on the thyroid gland in thyrotoxicosis was gradually gaining acceptance and in 1906 Schultze was able to say: 'Clinically, it makes no difference whether the secretion of the gland is increased or altered or is altered chemically as the result of changes in the blood, in the alimentary canal or in the central nervous system, the fact remains that the removal of the growing gland does away with the symptoms and upon failure to remove the diseased gland depends the failure to cure'. ${ }^{28}$ This succinctly summarized the situation as seen from the rather practical point of view of the surgeon. It had some measure of scientific support. If one were to completely remove the thyroid, then myxoedema resulted and the picture presented by myxoedema was dramatically opposed to that seen in hyperthyroidism. If one were to feed thyroid extract in excess, then many of the clinical manifestations of Graves' Disease were produced. Finally, excision of part of the thyroid gland caused amelioration or cure of the thyro-intoxication and in some cases caused diminution in the exophthalmos. This all added up to an attractive wellrounded rationalization of the problem. Casting a shadow across this however, were the results of surgical therapy. The mortality was often appalling. Though infection was now fairly well controlled as a result of aseptic surgery (ushered in by the introduction of steam sterilization by von Bergmann in 1886), haemorrhage from the vascular and friable thyroid gland was often frightening. The technique of shelling out the large adenomatous or colloid goitres with ligature and division of the thyroid arteries and clamping the relatively avascular thyroid isthmus, found limited application in the surgery of the exophthalmic goitre. Many surgeons likened this procedure to operating on an enormous arteriovenous fistula in the neck and the blood loss was often sufficient to cause the death of the patient. Deaths resulting from thyroid crisis after operation were not uncommon, nor were fatalities from the use of chloroform anaesthesia. The subjects themselves hardly made for safe operating. Treated for many years by physicians with an assortment of remedies that were often 


\section{D. A. Vellar}

dangerous as well as being useless, they were grossly emaciated and waterlogged from congestive cardiac failure before they were offered, almost as ritual sacrifices, to the surgeons. These were truly the 'last resort' cases which gave surgery of toxic goitre such an evil reputation.

Kocher undoubtedly had the greatest influence in the early development of thyroid surgery in America. Kocher stated that he could cure 75 per cent of his patients suffering from toxic goitre by removal of one lobe and perhaps a ligature of the superior thyroid vessels on the contralateral side. At Rochester, Minnesota, Charles and William Mayo had operated on some 110 cases of exophthalmic goitre between 1890 and 1907. ${ }^{29}$ Ether anaesthesia was routinely used. The mortality was nine per cent and the standard operation was removal of one lobe. In the severe cases, they followed Kocher's advice by ligating the superior thyroid vessels as a preliminary measure. By 1909, Charles Mayo was able to report on 400 cases of hyperthyroidism treated surgically. The mortality was now five per cent. Some of these cases were treated by a bilateral ligation of the superior thyroid vessels as the definitive procedure. Others had a lobectomy plus ligation of the opposite superior thyroid vessels. This ligation was carried out at a second operation for continuing toxicity after the removal of a single lobe. The vast majority had a single lobectomy performed. Mayo claimed a 70 per cent cure. In 1910, Charles Mayo described his current practice in managing hyperthyroidism..$^{30}$ Early cases were treated by a ligature of the superior thyroid vessels alone and this was still employed as a preliminary before excisional surgery in severe thyrotoxicosis. The usual operation was excision of one lobe and the isthmus. Mayo wrote: 'Some few cases do not recover their normal health after operation because either too little of the gland was removed or the remaining portion of the gland increased its size and output of secretion. Such cases require ligation of some of the vessels, and a resection of the remaining lobe may even be necessary at a later period'. His mortality following lobectomy was now 3.9 per cent. This paper of Mayo's mentions for the first time the need for an attack on the second lobe if the patient were to relapse. Three years later in 1913, the standard operation by Charles Mayo was still excision of one lobe and the isthmus. ${ }^{31}$ Relapses were treated by ligature of the inferior thyroid artery and removal of half of the remaining lobe. The pre-operative preparation of severely toxic patients is of interest. Irradiation of the thyroid was sometimes used in an attempt to improve the patient. In the more severe cases, Porter's technique was employed. This involved the injection of boiling water into the thyroid to produce necrosis of the gland and, it was hoped, diminution in thyroid activity. ${ }^{32}$ It is incredible that the technique of Porter based on the Wyeth injection of angiomata with boiling water, did not kill more patients by producing uncontrollable crisis. Charles Mayo's mortality for surgery of thyrotoxicosis was now three per cent and he claimed 75 per cent cures.

In 1913 he also employed the cervical sympathectomy operation of Jonnesco, not to control the thyrotoxicosis as Jaboulay claimed, but to improve the gross exophthalmos. ${ }^{33}$ This he hoped to achieve by the ptosis resulting from the operation and by the paralysis of the mythical muscle of Müller. In summary, the operative management of the patient suffering from thyrotoxicosis at Rochester up to the outbreak of the Great War was based on the following principles. 


\section{Thomas Peel Dunhill, the Forgotten Man of Thyroid Surgery}

First, the patients were never subjected to operation during an exacerbation of the thyrotoxicosis. Then, if bed-rest did not induce a remission, Roentgen irradiation and injections of boiling water were employed. If the case was very severe, preliminary ligation of the superior thyroid vessels was performed and then the patient was subjected to thyroidectomy. Balfour described thyroidectomy as follows: 'In our clinic the removal of a large part of the hyperactive gland is practised. The entire right lobe, isthmus and a part of the left lobe, sometimes as much as 4/5ths of the gland, should be removed as a rule'. He continues: 'Practically never is less gland retained than the size of the normal gland', and finally outlines the management of the recurrent toxicity: 'Should a recurrence of symptoms take place due to over-activity of the remaining portion of the gland, a resection of a portion of the remnant may be made'. ${ }^{34}$ The cure rate was quoted as 75 per cent and the operative mortality one per cent. This is the first time that a bilateral attack on the thyroid is mentioned at Rochester. However, a large remnant was obviously left behind (equal to the size of a normal gland). Whether this was dictated by fear of removing too much gland and thus rendering the patient myxoedematous, or failure to realize that in thyrotoxicosis a very small amount of the hyperplastic thyroid gland serves quite admirably in maintaining normal thyroid function, is difficult to ascertain.

By 1918, the standard technique at the Mayo Clinic for toxic goitre consisted of removal of the larger lobe, the isthmus, and part of the second lobe. ${ }^{35}$ In the case of simple goitre, a Mikulicz-type resection, leaving behind the posterior portion of each lateral lobe, was carried out. By 1920, the Mikulicz technique was applied also to toxic goitre. ${ }^{36}$ In the space of thirty years, Charles Mayo had moved from the employment of the Kocher technique, namely, excision of a single lobe for toxic goitre, to the Mikulicz technique leaving behind the posterior part of each lateral lobe, thereby initiating the modern surgical attack for thyrotoxicosis in America.

The other two members of the triumvirate often mentioned by some American authors as being the responsible founders of thyroid surgery in exophthalmic goitre were Halsted and Crile. William Stewart Halsted with Frank Hartley and Richard Hall introduced cocaine to general surgery in $1885-1886 .{ }^{37}$ Halsted also pioneered nerve-block anaesthesia. All three became addicted to cocaine. Halsted, with the help of William Henry Welch, the great pathologist at Johns Hopkins, cured himself of the addiction, but Hall and Hartley eventually died. Frank Hartley was a dashing swashbuckling surgeon. He was an early hero of the Mayo brothers. However, his erratic behaviour caused both Charles and William Mayo to become disenchanted with Hartley as a surgeon. As early as 1905 , Hartley had written an interesting article entitled 'Thyroidectomy for exophthalmic goitre'.$^{38}$ Hartley had operated on twentyone cases of exophthalmic goitre between 1887 and 1905, with one death. In five of these cases, Hartley performed a simultaneous attack on both lobes of the thyroid. He probably removed the whole of one lobe and varying amounts of the other. He claimed a 90 per cent cure rate and was one of the earliest surgeons to point out that cure in Graves' Disease depended on removal of a sufficient amount of thyroid gland.

Halsted went to the Johns Hopkins Hospital in Baltimore in 1887. Up to 1889 only seven goitre operations had been performed in Halsted's unit, six by Halsted and one by Harvey Cushing. Almost certainly these were lobectomies by the Kocher technique. 


\section{D. A. Vellar}

Halsted became interested in the blood supply of the thyroid and the recently discovered parathyroid glands. As a result of injection studies carried out by Halsted and Evans, who was a medical student at the Johns Hopkins, the blood supply to the parathyroids was finally elucidated. ${ }^{39}$ Halsted considered that post-operative tetany developed far more commonly as a result of interference with the blood supply of the parathyroids, rather than from their total removal. He therefore advocated 'ultra ligation' of the thyroid arteries distal to the points of take-off of the parathyroid arteries themselves.

He combined this with leaving a slice of the thyroid lobe behind to protect the parathyroids and of course the recurrent laryngeal nerve as well. Halsted never ligated the trunk of the inferior thyroid artery. Halsted stated: 'For the removal of a thyroid lobe in a moderately difficult case of exophthalmic goitre, ten minutes is ample time if the experienced skilful operator is well assisted'-one may comment that this seems to be brilliantly fast operating for a surgeon who was such a notoriously slow operator that it was said that the top half of his abdominal incisions were invariably healed by the time he had completed sewing together the bottom half! It is possible to follow the evolution of Halsted's operative technique through his various publications. In 1907 in a paper entitled 'Surgical tetany and the parathyroids', Halsted advocated single lobectomy for toxic goitre, leaving the posterior part of the gland behind. ${ }^{40} \mathrm{He}$ had performed ninety operations for toxic goitre between 1892 and 1907. His mortality was just over two per cent. Again in 1912 Halsted mentioned the operation for exophthalmic goitre.41 On this occasion he described the removal of the second lobe if the patient had not benefited from an attack on one lobe. It is apparent that an attack on the second lobe almost certainly performed at a separate (second) operation, was not Halsted's standard operation for exophthalmic goitre. This remained sub-total removal of one lobe and one lobe only. This is well documented in a curious paper entitled: 'The excision of both lobes of the thyroid gland for the cure of Graves' Disease'.42 Here it is stated that between 1902 and 1913 Halsted had to attack at two or more operations the greater portion of both lobes of the thyroid gland in thirty-nine cases of Graves' Disease, a minute experience as will be seen when compared to the operative experience of Dunhill. Finally, in a paper entitled 'The significance of the thymus in Graves' Disease' in 1914, Halsted stated that he had operated on 500 cases of Graves' Disease. ${ }^{43}$ Sixty per cent were cured by a single lobectomy, but forty-seven required excision of the second lobe as the response to a unilateral attack was unsatisfactory. Halsted noted: 'It is undoubtedly because surgeons have so universally confined their operations to the excision of one lobe plus perhaps the ligation of an artery of the other that the results have not been better than they are'. Dunhill, of course, had realized this as far back as 1907 . To conclude, Halsted in the magnus opus titled The Operative Story of Goitre-the Author's Operation written in 1920, depicted his operation both diagrammatically and descriptively. A sub-total excision of one lobe appears to be the standard procedure. The second lobe is attacked at a second operation. Certainly Halsted cannot claim priority (for what it is worth) of initiating a simultaneous attack on the second lobe in exophthalmic goitre.

George Washington Crile was the direct antithesis of Halsted. Crile, an extrovert, 


\section{Thomas Peel Dunhill, the Forgotten Man of Thyroid Surgery}

revelled in operating before large audiences. Halsted appeared to be the mechanical plodder, while Crile was the committed enthusiast. Halsted was the surgical product of an era when anatomy and pathology dominated medicine. Crile grappled with physico-biochemical aspects of disease and even as an operating surgeon was able to hold his own with the physiologists and biochemists of his day. In 1911, Crile wrote an article entitled 'Graves' Disease-a new principle of operation based on a study of 352 operations' ${ }^{44}$ He claimed that fear plus the apparent impulses derived from the thyroid gland, caused an overactivity of the sympathetic supply to the thyroid gland. This overactivity released the thyroid secretion and this caused the hyperthyroidism so often seen after operations on toxic goitres. Crile therefore developed his system of stealing the gland under 'anoci association' anaesthesia. The patient was given pre-operative inhalations of various sorts. On the day of the operation, the innocuous inhalations were substituted by ether. The patient was therefore anaesthetised in bed, the ether then changed to nitrous oxide, and oxygen, and the field of operation infiltrated with local anaesthetic. One lobe only was removed. Crile's technique was the same as Kocher's. He then attempted to leave behind pieces of the upper and lower poles of the thyroid to protect the parathyroids and recurrent laryngeal nerve. Finally, in 1922, Crile adopted the Mikulicz technique, leaving behind the posterior part of both lobes. ${ }^{45} \mathrm{In}$ essence, the use of local anaesthesia plus light general anaesthesia helped to avoid anaesthetic disasters and Crile practised a relatively bloodless thyroidectomy by using a large number of artery forceps as he clipped and cut his way through the lobe of the thyroid. He had a mortality of 1.8 per cent for toxic goitre. Like Kocher and Charles Mayo, Crile believed in preliminary ligation of the superior thyroid vessels if the toxicity was severe.

Though the surgery of toxic goitre had shown a vast improvement in morbidity and mortality in America, and the experience of surgeons like Charles Mayo and George Crile ran into thousands, little progress had been made in England. The leading thyroid surgeon at this time was James Berry. As late as 1913 in the Lettsomian Lectures on 'The Surgery of the Thyroid Gland with Special Reference to Exophthalmic Goitre', Berry could only muster sixty cases of thyrotoxicosis to the end of $1912 .{ }^{46}$ Twenty-seven of these were described as suffering from exophthalmic goitre. Two patients died. At St. Thomas's Hospital between 1908 and 1912, nineteen patients with toxic goitre had been subjected to operation with a mortality of 33 per cent. ${ }^{47}$ The reason behind this high mortality appeared to be the relative inexperience on the part of the English surgeons, anaesthetic disasters and the 'last resort' type of case that was continually handed over by the attending physician. The English surgeons were the victims of the misconception that the majority of the cases of exophthalmic goitre got better without surgery. A vicious circle was set up. Patients were operated on very late, the mortality was predictably high and so the physicians refused to refer patients for early operation.

Like America, the early development of thyroid surgery in Australia was strongly influenced by the experiences of Theodor Kocher. One of the earliest articles relating to the thyroid appeared in 1882 and was simply titled 'Case of myxoedema' by James D. Dunlop. ${ }^{48}$ The first account of successful removal of a goitre is contained in an article by T. N. Fitzgerald,* which appeared in $1884 .{ }^{49}$ This operation was

*Sir Thomas Naghten Fitzgerald (1838-1908). Irish surgeon who migrated to Australia. Appointed 


\section{D. A. Vellar}

carried out for a non-toxic goitre causing difficulty in breathing. Fitzgerald followed Billroth's technique closely and appears to have removed at least one lobe after twenty minutes of careful dissection. There is some evidence that this may indeed have been a total excision of the thyroid. In the discussion that followed, Dr. Jamieson of the Melbourne Hospital mentioned Kocher's experience with total thyroidectomy and the cachexia strumi priva following this procedure. He drew attention to the close resemblance of the clinical picture following this procedure to the myxoedema recently described by William Ord in England. Dr. Edward Barker, ${ }^{*}$ surgeon to the Melbourne Hospital and former pupil of the great Robert Liston, then stated that he had removed the thyroid on two occasions, the first in 1864 and the second in 1869. He stated that both patients died within two years of the operation from 'exhaustion'. It is unfortunate that Barker did not provide a fuller description of the state of these two patients as he may have been describing post-operative myxoedema following total thyroidectomy, at least ten years before Kocher's case of 1874 .

Fitzgerald mentioned that he had excised the thyroid (?how much) on three occasions prior to the case he presented. He had had some trouble with haemorrhage in one case but all eventually recovered and all were well. It would seem that these operations were not total removals. Fitzgerald, a brilliant and dextrous operator, advocated operation in every case of symptomatic goitre. As usual he tended to play down the technical difficulties and although he used the Billroth technique of en masse ligation of the thyroid tissue, he did not operate on the toxic goitre. The first account of exophthalmic goitre appearing in the Australian literature is represented by an article in the Australasian Medical Gazette for $1885-1886$ by W. Simpson Flett.50 The author devoted himself to the medical treatment current at that time, stressing the need for attention to diet and hygiene and Flett mentions the use of ammonio-citrate of iron for the anaemia, belladonna for palpitations, potassium iodide or potassium bromide to shrink the gland, and digitalis for swollen feet. External applications of tincture of iodine to the thyroid and the use of electricity to the gland are also described. The author in common with most of his colleagues regarded surgery as a last resort type of therapy, mentioning the cachexia strumi priva described by Kocher and Reverdin, which followed total extirpation of the gland.

One can sympathize with the physician unhappily pursuing a course between the Scylla of not operating on the severe thyrotoxic and the Charybdis of patients dying during or shortly after surgery for thyrotoxicosis. In the decade 1890-1900 the attention and interests of most physicians were concentrated on myxoedema and cretinism and the application of thyroid substitution therapy. Some of the difficulties encountered in thyroid therapy are pointed out by Lendon. ${ }^{51} \mathrm{He}$ tells how a country patient of his suffering from myxoedema was apparently failing to respond to the ingestion of fresh sheep's thyroid, until he discovered she was ingesting the submandibular salivary glands. When the patient corrected this error in anatomy, she improved rapidly!

surgeon to the Melbourne Hospital. Brilliant technician who was never quite converted to the antiseptic school of surgery. Reputed to have earned one million pounds during his surgical lifetime. Taught G. A. Syme and William Moore.

*Edward Barker (1818-1885). English surgeon who trained at University College Hospital before migrating to Victoria in 1840 . He became the first lecturer in surgery to the University of Melbourne. 


\section{Thomas Peel Dunhill, the Forgotten Man of Thyroid Surgery}

The first account of thyroidectomy for Graves' Disease in the Australasian literature appears in the Transactions of the Inter-colonial Medical Congress of 1896. In a rather skimpy article, Albert Martin described excision of one lobe of the thyroid. ${ }^{52} \mathrm{He}$ made no attempt to dissect the vessels but used an aneurysm needle and en masse ligation to remove the lobe. In the same issue, J. O. Closs of Dunedin described four cases of Graves' Disease treated by excision of one lobe. ${ }^{53}$ There was one death due to post-operative thyroid crisis. He followed Kocher's technique closely in preference to the Mikulicz resection. The first reported thyroidectomy for Graves' Disease in Australia emanated from Bendigo, Victoria. Here in 1897, an intrepid surgeon named W. J. Long,* operated on a case of exophthalmic goitre. ${ }^{54}$ He removed one lobe of the thyroid and the related recurrent laryngeal nerve as well. The patient, a young woman, had a post-operative crisis but recovered from this and was much improved, but was left somewhat hoarse. Chloroform was the anaesthetic agent. It can be readily seen that though there were a few cases of successful removal of the thyroid or part of the thyroid for non-toxic goitre causing pressure symptoms, operation was rarely practised for exophthalmic goitre. Haemorrhage, post-operative crises and death on the table from chloroform anaesthesia plagued the surgeon who dared to operate. Current medical thinking at that time is reflected in a review of James Berry's book Diseases of the Thyroid Gland and Their Surgical Management. ${ }^{55}$ The reviewer deplores the fact that Berry fails to quote the Australian experience with regard to hydatid disease of the thyroid! He agrees however, with Berry's assertion that surgical treatment was worse than useless in exophthalmic goitre. The reviewer then states that: 'Many operations have been practised in these cases and the larger ones are very dangerous and whilst good results have followed in some cases, these are insufficient to justify the risk. Also there is a strong tendency towards recovery'. This then was the state of affairs in Australia when Dunhill commenced his medical studies.

Thomas Peel Dunhill graduated in 1903 from the Clinical School of the old Melbourne Hospital. Like Sir Hugh Devine, ${ }^{* *}$ whom he influenced so much, Dunhill completed a course in pharmacy before entering medicine. Dunhill obtained passes in theory and practice of medicine, surgery, obstetrics and diseases of women and children as well as in forensic medicine. At the honours examination held in the first term of 1904 he obtained First Class Honours in medicine, surgery and obstetrics and in diseases of women and children. Aged twenty-seven, he was older than the usual medical graduate and had already published an article as a medical student on 'Albuminuria following severe exercise in healthy persons'. ${ }^{.6}$ His surgical residency at the Melbourne Hospital was spent with William Moore. It was probably during this period that the problems in the management of exophthalmic goitre first attracted him. He recalled many years later how he had seen his chief 'of indomitable courage' operate on two cases of toxic goitre under chloroform anaesthesia. Both patients had

*W. J. Long. Graduated from the University of Melbourne in 1892 and then practised as a surgeon in Bendigo, a Victorian provincial centre. Elected a Fellow of the Royal Australasian College of Surgeons in 1928.

** Sir Hugh Berchmans Devine (1878-1959). Surgeon to St. Vincent's Hospital, Melbourne. He became the leading abdominal surgeon in Australia and devised the Devine Frame, a square metal retractor to aid and facilitate exposure in the abdomen. 


\section{D. A. Vellar}

died. Having completed his residency at the Melbourne Hospital, Dunhill had to decide where his future in medicine lay. Not being wealthy (he came from 'Tragowell', a sheep and cattle station near Kerang in north-east Victoria) and not having connexions of the right kind, he left the Melbourne Hospital and accepted the invitation of Mother Berchmans Daly to join the staff of St. Vincent's Hospital. Although he had already decided to pursue a career in surgery, as there were no surgical vacancies at St. Vincent's at that time, he was appointed in 1905 physician to outpatients, and anaesthetist. By 1906, he was listed as surgeon to outpatients and surgical pathologist. His chief was now David Murray Morton. In the same year he was awarded his Doctorate in Medicine for a thesis entitled 'An Investigation of Opsonic Indices as a Guide to Therapeutic Innoculation by Vaccines with some Results of Innoculation'. He was now about to embark on his life's work with thyrotoxicosis, which legitimately entitles him to be ranked with Kocher, Mayo, Crile and Halsted.

St. Vincent's Hospital, Melbourne, was officially opened on 5 November 1893 . The first Rectress, Mother M. Berchmans Daly, was appointed in 1892. It would not be exaggerating to say that the foundation of the hospital and its continuing success was entirely due to the efforts of this first Rectress. She proved to be an extraordinary organizer, an indefatigable worker and showed a rare insight in the appointment of staff to the new hospital. It was on account of her that Thomas Dunhill and Hugh Devine were able to make their mark in surgery. Whilst Dunhill was an outpatient physician, he became interested, naturally, in the management of exophthalmic goitre. The medical management at that time reflected the total lack of specific therapy and this of course resulted from a lack of understanding of thyroid function. The list of remedies which at one time or another were claimed as specific for the patient with exophthalmic goitre, was truly impressive. Kocher had warned of the danger of using iodides in goitre patients and this probably delayed the exhibition of iodides in toxic goitre for many years until Henry Plummer reintroduced this method of treatment in 1923. ${ }^{57}$ Sodium phosphate, sodium chloride, ergot, belladonna, morphia and bromides were used in conjunction with rest in bed and a milk diet. Ice-bags placed on the neck and over the praecordium were also in vogue. Aconite, stropanthus and digitalis were also used. Finally, faradic currents and tincture of iodine were applied locally to the gland. Almost certainly any amelioration resulted from a spontaneous remission or from the disease process burning itself out. Whilst this uncommon event was awaited, the severe thyrotoxics, often grossly emaciated and perhaps blind from the corneal ulceration, succumbed to intercurrent pulmonary infection, cardiac failure or from the uncontrollable vomiting and diarrhoea, coma and hyperpyrexia of uncontrolled thyroid crisis.

Invoking the theory that the body normally produces some factor that neutralized the thyroid toxin responsible for the production of the clinical signs of exophthalmic goitre, physicians introduced a host of remedies derived mainly from animals that had had the thyroid gland removed. The first of these remedies was the milk of thyroidectomized goats marketed commercially as Rodagen. Another preparation was called Thyroidectin and this was prepared from the serum of thyroidectomized animals. It was taken orally. At about this time, 1906, Beebe from New York advocated the use of cytolytic serum. ${ }^{58}$ This was obtained by injecting an animal with thyroid extract and then 


\section{Thomas Peel Dunhill, the Forgotten Man of Thyroid Surgery}

injecting the serum of this animal into a patient suffering from toxic goitre. Though holding some theoretical attraction, this method too was eventually discarded. The same fate awaited the use of adrenaline, thymus extracts and parathyroid extracts. Dunhill, on the advice of Dr. Grant and Dr. Maudsley, the in-patient physicians at St. Vincent's at that time, had been giving the milk of thyroidectomized goats to a group of patients suffering from exophthalmic goitre. Dunhill used to operate on the goats at Melbourne University and after he had removed the thyroid and the goat recovered, he would milk the goat himself and return to St. Vincent's, there to distribute the milk to thyrotoxic patients. By 1907, Dunhill had realized the inefficiency of medical treatment available at that time for patients suffering from thyrotoxicosis. He was also impressed by Kocher's results in operations on the thyroid using local anaesthesia and of course he had seen the disasters which had accompanied general anaesthesia in the surgery of toxic goitre. It is readily understood now how the combination of anoxia, chloroform overdosage and cardiac failure often proved lethal. Dunhill had also read A. E. Barker's paper in the Practitioner of September 1907, which described the use of a mixture of eucaine and adrenaline ( $\frac{1}{2}$ per cent eucaine and 1 in 250,000 adrenaline) for local anaesthesia in thyroid surgery. ${ }^{59}$ Dunhill also doubted the claimed efficacy of other operative procedures on the thyroid gland such as the exteriorization of the gland and unilateral or bilateral cervical sympathectomy. These operations had been popularized by Jaboulay in his book Chirurgie du Grand Sympathetique et $d u$ Corps Thyroide. ${ }^{60}$ The operations on the cervical sympathetic chain, whilst producing a certain questionable cosmetic improvement by the ptosis produced, nevertheless failed to attack the site of disordered function. Disheartened by the results of medical treatment of Graves' Disease and guided by Kocher's experience with local anaesthesia, Dunhill embarked on his career as a thyroid surgeon. As an outpatient surgeon at St. Vincent's, he had no beds. He was allowed the use of a bed by his chief, David Murray Morton.* Into this bed, situated on a balcony leading off from St. Clare's female ward, was admitted a thirty-six-year-old Irish servant girl, Mary Lynch. She had been admitted under the care of Dr. Grant with exophthalmic goitre on 25 March 1907. Despite the usual rest in bed, sodium phosphate, sodium bromide, Rodagen and thyroidectin, she continued to lose weight and commenced vomiting. In Dunhill's own words: 'She was emaciated and had all the symptoms in an extreme degree. She could not work. She preferred any risk to remaining as she was'. On 30 July 1907, with the assistance of Murray Morton, Dunhill removed the right lobe of the thyroid under eucaine and adrenaline anaesthesia. He also noted that after this operation the patient was able to get up from the operating table and walk back to her own bed! The hospital record of this event (fig. 2) is the very essence of brevity. The house surgeon's signature belongs to Dr. A. E. Harker. 'Exopthalmos' is of course spelt incorrectly, and R. D. signifies 'Relieved Discharged'.

This operation of Dunhill's was the fourth thyroidectomy performed at St. Vincent's Hospital since its inception in 1893. The first thyroidectomy (consisting of removal of the left lobe) was carried out by G. A. Syme** on 3 April 1902. This was for a non-toxic

*David Murray Morton (1871-1959). General practitioner who later became senior surgeon at St. Vincent's Hospital, Melbourne. Assisted Dunhill during his first thyroidectomy. Foundation Fellow of the Royal Australasian College of Surgeons.

**Sir George Adlington Syme (1859-1929). A pupil of Sir Thomas Naghten Fitzgerald, he was 


\section{D. A. Vellar}

goitre; chloroform was used and the patient recovered. The first thyroidectomy for thyrotoxicosis was performed by William Moore,* Dunhill's chief at the Melbourne Hospital, who was also an in-patient surgeon to St. Vincent's Hospital at that time. This was performed on 14 June 1904 and chloroform anaesthesia was used. The patient, a woman in her thirties, was three months pregnant. She had moderately severe thyrotoxicosis. One lobe was removed. There was a mild, post-operative crisis which she was able to survive and she was discharged relieved. The third thyroidectomy ended tragically. A seventeen-year-old girl with severe thyrotoxicosis was operated on by William Moore under ether and chloroform anaesthesia. She collapsed and died as the operation was being completed. The fourth thyroidectomy was of course Dunhill's first operation on Miss Lynch. It took no small amount of courage to attempt a thyroidectomy on such a severely thyrotoxic patient. The local statistics for the surgery of exophthalmic goitre were hardly encouraging and the medical attitude dictated that surgery was to be regarded as the last throw of the dice. The secret of Dunhill's continuing success lay in his technique. Instead of the scalpel and forceps dissection of the goitre which often produced disastrous bleeding from the fragile, dilated arteries and veins, he dislocated the gland by gentle finger dissection, dissected cleanly the vascular pedicle and early in the operation ligated and cut both the superior and inferior thyroid arteries. His lobectomy was thus gently executed and relatively bloodless.

Dunhill published his first article on thyroidectomy in exophthalmic goitre in the Inter-colonial Medical Journal of Australasia, 20 November $1907 .{ }^{61} \mathrm{He}$ had by then operated on seven cases, all under local anaesthesia. These cases constituted a type of surgical chain reaction. When Dunhill had operated successfully on Miss Lynch, all the other patients after seeing the improvement which surgery had effected, submitted themselves, one by one, to operation! All of these cases had severe thyrotoxicosis, all had one lobe and the isthmus removed, all recovered and the short-term results were good, there being a gratifying reduction in the pulse rate plus significant weight gain. In the space of six months, Dunhill performed more successful operations on patients with exophthalmic goitre than the combined experience of the Melbourne Hospital, the Alfred Hospital and the Homeopathic Hospital since the inception of those institutions. Most important, his mortality was nil. This was sufficient to merit editorial comment in the same issue. ${ }^{62}$ With a not surprising 'middle of the road' bias the following comments were made: 'The difficulty in estimating the possible value of such surgical procedure as described by T. P. Dunhill lies in the fact that there is still room for difference of opinion as to the part played by the thyroid gland in producing the symptom complex characteristic of the affection. How far the result in Dr. Dunhill's cases will be curative remains to be seen. It is not to be desired that a cacoethes seccandi should immediately attach to the treatment of Graves' Disease, but the

successively inpatient surgeon to St. Vincent's Hospital and the Melbourne Hospital. In 1894 he performed the first successful excision of a meningioma in Australia. Became the first President of the Royal Australasian College of Surgeons.

*William Moore (1859-1927). Inpatient surgeon to St. Vincent's Hospital and the Melbourne Hospital. As Dunhill's chief he helped to stimulate his interest in the thyroid gland. Was instrumental in eliminating the bribery and corruption which attended the election of medical staff to the Melbourne Hospital. 


\section{Thomas Peel Dunhill, the Forgotten Man of Thyroid Surgery}

careful observations of a series of cases by any one surgeon would do much to clear up some uncertainty as to the probable benefit and possible danger'. Dunhill was more than equal to the challenge. He had realized that the use of local anaesthesia had eliminated the risk of death from the use of chloroform, and that one lobe and the isthmus could be removed bloodlessly by ligation and division of the thyroid arteries and veins and then dislocating the gland forwards and medially. He had also not hesitated to operate on two patients with auricular fibrillation, a condition which practically contraindicated operation in Kocher's view. Both of these patients survived. Dunhill's next communication was titled 'The surgical treatment of exophthalmic goitre' and this was published in $1908 .{ }^{63}$ This is a sober, well-reasoned article, opening with a review of the then recent literature showing the rationale of the operative treatment of Graves' Disease and finally he discusses his own cases. In the year since he had operated on Miss Lynch, he had performed lobectomy thirty-two times in twenty-five patients. He had had one death, his thirteenth case. All the patients were severely thyrotoxic. All had initially the larger lobe and the isthmus removed. However, in six patients, a second operation was required in which at least half of the remaining lobe was ablated. Dunhill had, by this stage, grasped the essence of the problem-enough gland had to be removed to cure the patient. In the six cases, the initial improvement was not maintained after a single lobe had been excised. Dunhill did not hesitate to remove part of the remaining lobe to effect a cure. His third case, a women aged thirty-five, had one lobe and the isthmus removed on 10 October 1907. She failed to maintain the initial improvement and so had most of the remaining lobe removed under local anaesthesia on 17 December 1907. The famous Miss Lynch eventually returned to have most of the remaining lobe removed in March 1908. Again, unlike Kocher and Charles Mayo, who regarded cardiac failure and an irregular pulse as contraindications to surgery, Dunhill insisted that a marked improvement in the cardiac state could follow if the thyrotoxicosis was controlled by adequate removal of the gland. Two of his cases were in extremis in gross cardiac failure with auricular fibrillation, yet both withstood removal of one lobe and isthmus under local anaesthesia and showed marked improvement. The one death ironically appears to be associated with his first attempt to perform a simultaneous bilateral attack on the thyroid. In a case of severe thyrotoxicosis with bilateral enlargement of the gland, Dunhill removed one lobe, the isthmus and half the second lobe in one operation. The patient subsequently died in thyroid crisis. Dunhill thought that this resulted from trying to do too much at one time and reflected that a staged attack might have produced happier results. Dunhill insisted that the operation should never be regarded as a last resort and pleaded for early surgical intervention. Of his first twenty-five patients operated on for thyrotoxicosis, only five were referred by his medical colleagues. All the others were directly or indirectly referred by his first six successful cases. These ideas were even more forcefully presented to the Eighth Australasian Medical Congress held in Melbourne in October 1908.64 At this time, Dunhill had performed forty-seven thyroidectomies for exophthalmic goitre. Ten of these operations were second operations on the remaining lobe of the thyroid because the patient had relapsed after a single lobectomy. In contrast, Charles Mayo, reporting on his experiences in 1909, recommended ligation of the superior thyroid vessels to the 


\section{D. A. Vellar}

remaining lobe to control any relapse after a single lobe had been removed. Dunhill vehemently denied that simple ligation could control recurrent thyrotoxicosis. At this time, knowledge of the physiology and biochemistry of the thyroid was rudimentary. Surgeons knew that if the whole thyroid was excised, then myxoedema and tetany followed. Just how much thyroid one could remove without causing these dreaded complications was not known. In 1908 Dunhill had attempted to rationalize the attack on the second lobe by incriminating the size of the lobe. ${ }^{65} \mathrm{He}$ wrote: ' $\mathrm{I}$ had just begun to recognize that in a large bilateral vascular goitre, the removal of one lobe was not enough to cure the case. The disease being a thyrotoxicosis, the large vascular lobe which remains is still larger than a normal thyroid and pours out thyrotoxic material sufficient to cause all the symptoms of exophthalmic goitre'. Thyroxine had not yet been discovered and it was widely thought that the secretion of a toxin from the thyroid lay at the root cause of exophthalmic goitre. Not only was Dunhill advocating an attack on the second lobe (unlike the American authorities such as Mayo, Crile and Halsted who were content to perform a single lobectomy and a ligation of the superior or inferior thyroid vessels for relapse) he strongly advised surgery for the thyrocardiac. Dunhill indeed was the first surgeon to convincingly demonstrate the efficacy of thyroidectomy in the thyrocardiac patient.

By 1909 Dunhill's exploits were filtering through to the general public. He was the only person in Victoria, probably Australia, who was consistently curing or greatly improving patients suffering from exophthalmic goitre by safe operating. He made his first contribution to the international literature in 1909, in a paper entitled 'Remarks on partial thyroidectomy, with special reference to exophthalmic goitre and observations on 113 operations under local anaesthesia' ${ }^{66} \mathrm{He}$ had by then performed eightyeight operations on patients suffering from exophthalmic goitre, by far the largest experience of any Australasian surgeon. Half of these cases were physician referred, a major breakthrough in medical education. Once again, he reiterates in this article the rationale of his operative therapy for exophthalmic goitre, the necessity for early operation if the case fails to respond to rest, the importance of removing enough of the gland, and despite the death of his thirteenth case, as a result of the experience gained he did not hesitate to complete the operation in one stage in suitable cases, removing one lobe, isthmus and at least one half of the other lobe. He wrote: 'Latterly, with increasing rapidity in operating, I have been removing one lobe, the isthmus and half of the second lobe at one operation, when I have judged that wise. The time taken and the amount of handling necessary for this are less than was required for the removal of one lobe in my earlier operations'; and again 'Of the exophthalmic cases, 52 were typical cases with classical symptoms, 15 of these 52 had part of the second lobe subsequently removed. Of this class I can say that in every case where the removal of the larger lobe has not effected a cure, the removal of part of the second lobe has done so (always excepting the one case which died). In many of the latter cases one and a half lobes were removed at one operation'.

Dunhill continued to operate on cases in cardiac failure and with auricular fibrillation and whereas authorities such as Kocher, William Osler and Charles Mayo regarded this as a more or less absolute contraindication to surgery, Dunhill convincingly demonstrated the curative effect of thyroidectomy in the thyrocardiac. 'Eight 


\section{Thomas Peel Dunhill, the Forgotten Man of Thyroid Surgery}

cases with irregular heart beats and pronounced oedema, of these 4 had part of the second lobe subsequently removed: one had a third operation because the upper lobe left after the second operation was unsightly. The original goitre had been of immense size. Every one of these stood the operation well'.

To summarize, by 1909 Dunhill had grasped the necessity for early operation, was carrying out a one-stage bilateral attack on the thyroid in exophthalmic goitre in selected cases and he did not hesitate to operate on the thyrocardiac. Cases were now coming to Dunhill from all over Australia and New Zealand. By 1910, Dunhill had performed 312 operations on the thyroid, 200 being on exophthalmic goitre. ${ }^{67} \mathrm{He}$ had lost only three patients! One died of pneumonia post-operatively, two were moribund when subjected to surgery, the typical last resort cases which Dunhill was trying to eliminate by earlier surgery. The same message is hammered home-earlier surgery if the patient is not responding to conservative management, the necessity for local anaesthesia, the importance of avoiding surgery at the height of a crisis or if bronchitis was present and the necessity to remove enough thyroid. This meant removing one lobe and at least one-half to two-thirds of the other lobe at one operation. Dunhill stated: 'The operation must frequently result in failure if only one lobe is removed, the other lobe at the same time being large and vascular. Removal of one lobe may not do a patient any good at all, and it is because one whole lobe is generally left that the operation is frequently spoken of as not being successful. That I should think is the explanation of the statement which occurs in the British Medical Journal of 1st October, 1910, where 13 cases were operated upon at St. Thomas's Hospital, 5 died, 5 improved and 3 remained in statu quo'. He had not encountered myxoedema or tetany in any of his cases, certainly his methods of operating ensured the survival of some thyroid and parathyroid tissue, the posterior aspect of the second lobe being left behind.

By the time 1910 had drawn to a close, a number of other important achievements involving Dunhill and St. Vincent's Hospital require to be noted. Firstly, Dunhill, with the help of Hugh Devine and the Mother Rectress of the hospital, had succeeded in having St. Vincent's Hospital recognized as a clinical school. The first clinical lecturers in surgery were Murray Morton and Douglas Shields, and the first surgical tutors T. P. Dunhill and Hugh Devine. Dunhill recalls this part of his life in a letter to Hugh Devine written some months before his death in 1957. He wrote: 'Those were great days. I remember spending most of my time during the first year or two on a continuous triangular circuit-Professor Allen at the University, Mother Berchmans at St. Vincent's and the Chief Medical Officer of the City Council [Colonel Norris] who finally gave what he called his "permissive tolerance" for the use of the semi basement at St. Vincent's for a teaching hospital'. 1910, of course, was also the year Dunhill and Hugh Devine assisted Douglas Shields when Shields operated on the Countess of Dudley and removed a stone from her ureter. Douglas Shields was then surgeon to the Governor General of Australia, even though he did not hold a senior surgical degree. ${ }^{68}$ Shields had to operate in the ballroom of Government House which had been converted into a makeshift operating theatre. This operation proved to be a success and the relieved Countess was later instrumental in setting up a private hospital for Douglas Shields in Park Lane when Shields moved to England in 1912. 


\section{D. A. Vellar}

During this time, Dunhill was steadily moving up the surgical pyramid. In 1906 he was surgeon to outpatients. In 1907 he is listed as junior surgeon to inpatients and in 1910 he is designated with Hugh Devine as assistant surgeon to inpatients. The surgeons to inpatients for that year consisted of David Murray Morton and Douglas Shields. David Murray Morton played an important role in encouraging Dunhill's interest and talents in the surgery of the thyroid. As has already been noted, it was he who gave Dunhill a bed so that Dunhill could operate on Miss Lynch and he actually assisted Dunhill at this operation. Dunhill decided to travel overseas in 1911 and to visit some of the thyroid centres in England and America. Whilst in England, he was supposed to deliver a paper before the surgical section of the Royal Society of Medicine on 3 February 1912. However, Dunhill was unable to be in London at this time and so the paper was delivered by James Berry, probably the most experienced thyroid surgeon in England at that time. ${ }^{69}$ In those days manuscripts were accepted and printed with alacrity, for the same paper entitled 'Partial thyroidectomy under local anaesthesia with special reference to exophthalmic goitre' appeared in the Lancet of 17 February $1912 .{ }^{70}$ It is virtually the paper he published in the Australian Medical Journal of 20 November 1910. The Lancet publication was obviously intended for English and American consumption in case the colonial literature had escaped them! The discussion that followed Dunhill's paper at the Royal Society of Medicine is of more than passing interest. Sir Victor Horsley opened the discussion. He agreed with Dunhill that the danger of operation was nil (!) but apparently he refused to operate on the really severe cases. Again, Horsley only removed one lobe. Horsley stated that true exophthalmic goitre often got well with Faradism and rest-cure treatment! $\mathrm{He}$ had seen no deaths from general anaesthesia. Horsley's experience in the surgery of exophthalmic goitre was minute when compared with Dunhill's and by not operating on the severe cases he certainly kept his mortality down. The remaining discussion appeared to be in Dunhill's favour. The surgeons participating, however, failed to mention their own figures, probably because their personal experiences were embarrassingly small.

On 27 February 1912, the discussion was continued by Dr. Hector MacKenzie. ${ }^{71}$ He queried the truth of some of Dunhill's claims and the reason for this is clear-the operative mortality at his own hospital, St. Thomas's, was appalling (six cases out of nineteen) and he obviously could not believe that this unknown surgeon from the colonies could claim only four deaths in 230 cases of exophthalmic goitre. MacKenzie was followed by Albert Kocher, the son of the great Swiss thyroid pioneer Theodor Kocher. Albert Kocher mentioned the experience at the Berne Klinik with Graves' Disease (800 cases). ${ }^{72}$ Operative treatment consisted in the main of removal of one lobe with perhaps ligation of the contralateral superior thyroid artery. Rarely was a second operation performed on the remaining lobe, but he stressed the difficulty of performing this second operation. No mention was made of a bilateral attack on the gland. Theodor Kocher was still dominated by the spectre of cachexia strumi privawhich was to haunt him till the end of his surgical career. The other English surgeons, such as Barker and Symonds contented themselves with discussion of their own minuscule experiences. Dunhill's record of only four deaths in 230 cases of exophthalmic goitre was ignored. Throughout the discussion ran a thick vein of incredulity at 


\section{Thomas Peel Dunhill, the Forgotten Man of Thyroid Surgery}

Dunhill's results and a thinly veiled suspicion of the truthfulness of his claims. James Berry then summarized the paper and discussion. ${ }^{73} \mathrm{He}$ himself had operated on only eleven cases of true exophthalmic goitre, and two had died. He said: 'It is a little difficult to reconcile the optimistic view of Dr. Dunhill with the actual results that are being obtained in this country by most of those who do from time to time operate for this disease. I can but congratulate Dr. Dunhill on the excellent results he has been able to obtain, although at the same time, with Dr. Hector MacKenzie, I wish that he had indicated a little more clearly how many of his cases really come under this category of genuine Graves' Disease'. James Berry crystallized his own philosophy in the management of exophthalmic goitre by stating: 'In the very great majority of the cases of true Graves' Disease which have come under my notice, I have declined to operate, as I have not considered that the benefits to be obtained justified the risks except in rare and isolated instances'. In reality, not one surgeon present at that meeting, with the possible exception of Albert Kocher, could remotely approach Dunhill's experience or results. As far as surgery of exophthalmic goitre was concerned, Dunhill was decades ahead of his English contemporaries and his mortality rate was one of the lowest in the world.

During his stay in England in 1911, Dunhill journeyed to Leeds to see Moynihan operate and to Edinburgh to see Stiles, before leaving for America on 27 August 1911. His English hosts entertained Dunhill to dinner, and a number of apocryphal stories have arisen from the encounter between Dunhill and Dr. Dickinson Berry, the anaesthetist wife of James Berry. She is purported to have remarked: 'Dr. Dunhill, you don't really operate on those dreadful people with the pop eyes do you?' A less kindly version has her telling Dunhill: 'Of course Graves' Disease is obviously much milder in Australia than it is in England'. ${ }^{74}$

During his stay in America, Dunhill visited all the leading surgical centres. He went to New York, Baltimore, Chicago and Rochester. He saw some of the leading surgeons there including Kelly, Cushing, Murphy, Halsted and the Mayo brothers. He met Halsted at Johns Hopkins and discussed with him the importance of the bilateral attack on the thyroid gland to achieve the best results in the treatment of exophthalmic goitre. He even gave Halsted reprints of his publications.

When Dunhill returned to England and had James Berry deliver his paper at the symposium on the thyroid gland arranged by the Royal Society of Medicine, this publication must certainly have come to Halsted's notice (and to the notice of the Mayo brothers and George Crile as well). Halsted, about a year later, published an article entitled: (1) 'The excision of both lobes of the thyroid gland for the cure of Graves' Disease' (II) 'The preliminary ligation of the thyroid arteries and of the inferior in preference to the superior artery'. ${ }^{75}$ This paper was read before the American Surgical Association on 7 May 1913. In effect, it stated that in thirty-nine cases of exophthalmic goitre operated on by Halsted, a staged removal of part of the second lobe became necessary to cure the disease. Dunhill had pointed this out six years earlier. Halsted's technique left behind the posterior part of each lobe to safeguard the parathyroid glands and the recurrent laryngeal nerve. Dunhill removed one lobe and the isthmus completely and one-half to two-thirds of the remaining lobe. As far as can be determined, Halsted did not attack both sides of the gland at the one operation and 


\section{D. A. Vellar}

certainly he did not precede Dunhill in pointing out the necessity for removing part of the second lobe. Indeed, 1912 appeared to be a watershed as far as publications concerning the surgery of exophthalmic goitre in America. Prior to this year, a onesided lobectomy with contralateral ligation appeared to be the standard operation for toxic goitre, not only by Halsted but also by Charles Mayo and Crile. Was it purely a coincidence that after Dunhill's visit to the American centres in 1912 that increasing mention is found of the need to remove sufficient thyroid tissue to effect a cure and in particular the need to attack the second lobe? This trend is reflected in an article by Balfour in 1914 emanating from the Mayo Clinic. ${ }^{76}$ For the first time, a definite statement is made concerning an attack on the second lobe of the thyroid in exophthalmic goitre. 'In our Clinic, the removal of a large part of the hyperactive gland is practised, the entire right lobe, isthmus and a part of the left lobe, sometimes as much as fourfifths of the gland, should be removed as a rule'. Dunhill had been doing this since the end of 1907 in favourable cases. Balfour claimed a 75 per cent cure rate with a mortality of 1 per cent.

On his return to St. Vincent's Hospital, Dunhill had advanced to become surgeon to inpatients to replace Douglas Shields who had left for England in 1912. Dunhill was now chairman of the medical staff at the young age of thirty-seven. His surgical career in Australia was now interrupted by the outbreak of the first World War. Dunhill was appointed to the 1st AIF in December 1914, with the rank of major. He was posted as surgeon to the First Australian General Hospital in 1915. At the time of his enlistment, Dunhill was firmly established as the leading goitre surgeon in Australasia. Unfortunately, his professional colleagues were not above the petty jealousies and resentment which his success invited. H. C. Hinder, surgeon to the Royal Prince Alfred Hospital, Sydney, wrote an article in 1913 entitled: 'The removal of the thyroid gland'. ${ }^{77}$ Hinder says, amongst other things, 'a considerable stir was created in the surgical world of Australia by the removal of the thyroid gland under local anaesthesia. It is very hard to say why, because thyroids had been removed both under local and general anaesthesia for years past, but when a few surgeons persisted in using the local method and persuaded themselves and the public that this method was attended by a very much lower mortality, men began to look into the matter'. Hinder failed to quote his experience in the surgery of toxic goitre. Dunhill's detractors failed to concede that it was his vast experience, combined with a superlative operative technique, plus the added safety of avoiding general anaesthesia that enabled him to salvage cases which would have certainly died in other surgeons' hands.

Dunhill went to Egypt with the First Australian General Hospital and there became ill (probably with nephritis). He was temporarily invalided back to Australia. Whilst in Egypt he had met McCarrison, whose theories and practices with regard to toxic goitre were directly opposed to his own. At a scientific meeting held in Melbourne on 3 May 1916, he contributed to the discussion on goitre and in particular exophthalmic goitre. ${ }^{78} \mathrm{He}$ gently demolished the theory that the septic focus in conjunction with the intestinal auto-intoxication theory of Arbuthnot Lane was the prime cause of exophthalmic goitre. Of course, he said, septic foci should be looked for, causes of worry removed and medical treatment given a reasonable trial, but if 


\section{Thomas Peel Dunhill, the Forgotten Man of Thyroid Surgery}

no improvement resulted, operation had to be resorted to. Dunhill embarked again for France in April 1917. He rejoined the First Australian General Hospital at Rouen and in September 1917 was promoted to Lieutenant Colonel. Despite his army commitments he still found time to write and pursue his interest in the thyroid. 'A discussion on the surgery of exophthalmic goitre' appeared in 1917.79 This is, as usual, a methodical, lucid account of the whole problem. Dunhill discusses the various theories proposed in the pathogenesis of exophthalmic goitre. He recognized the difficulty in incriminating the thyroid gland when the so-called 'toxin' from the thyroid had not been isolated. Kendall, working in Rochester, had actually isolated thyroxine in 1914. However, the physiological action of the hormone had not been fully elucidated in 1917. Medical thinking had been dominated by the necessarily rigid Koch postulations linking specific bacteria with specific disease entities, and this had played an important part in the activities of McCarrison and Arbuthnot Lane. As Dunhill had accumulated by now an impressive personal experience in thyroid surgery (1,500 operations) of which over one-half were on patients suffering from toxic goitre, he was able to speak with increased authority on the important factors which enabled a cure to be achieved by surgery in the thyrotoxic. Firstly there was the necessity for removing sufficient thyroid tissue. Dunhill stated that though some improvement may result from a unilateral lobectomy plus ligature of the arteries of the contralateral side, for cure to be achieved the bulk of the second lobe had often to be removed. Dunhill then discussed typical problems encountered by the thyroid surgeon, namely, patients with extreme emaciation, those with extreme proptosis which often progressed to corneal ulceration and the destruction of the eye, those requiring three operations before sufficient thyroid tissue was removed to make the patient euthyroid, and finally the cardiac cripple resulting from uncontrolled thyrotoxicosis and auricular fibrillation. As far as the latter was concerned. Dunhill stated that the congestive cardiac failure and anasarca could be completely controlled by thyroidectomy, the pulse itself often becoming perfectly regular after operation. In this article he destroys McCarrison's argument that 'There is no definite proof that the cures effected by surgical means (i.e. by hemithyroidectomy alone or with ligation of arteries) are more lasting than those effected by medical means'. Dunhill continued: 'One would like to point out in this report that hemi-thyroidectomy is not the operation which is performed for the cure of Graves' Disease. In 1909 I wrote in the British Medical Journal that it was necessary to remove a portion of the second lobe (always leaving behind sufficient for physiological purposes). Later Halsted wrote of the necessity for partial double lobectomy for the cure of the disease. The Mayos and Crile have written similarly.' One of the cases mentioned in this article was that of a nursing sister at the Middlesex Hospital. Dunhill was asked to see this patient by Dr. Pasteur, then the senior physician at the Middlesex. Pasteur thought the patient too ill to operate on. And his doubts were shared by the surgical staff at the Middlesex. Dunhill removed most of the thyroid in two operations and obtained a complete cure, thereby presaging the enormous effect he would have on thyroid surgery when he returned to England in 1920.

Dunhill saw out the rest of the war as consulting surgeon to the Rouen area. He arrived back in Melbourne on the Niagara on 11 August 1919. The remaining 


\section{D. A. Vellar}

months in Australia were somewhat turbulent and worrying for him. As a result of his war service, Dunhill had made the acquaintance of many leading British surgeons, in particular George Gask, surgeon to St. Bartholomew's Hospital. Gask had been appointed Professor of Surgery in charge of the surgical unit at St. Bartholomew's. He offered Dunhill the position of Assistant Director. Dunhill was forty-four years old, solidly established as a general surgeon in Melbourne and the leading thyroid surgeon in Australasia. The conditions of the appointment are interesting. He had to obtain the English Fellowship and he had to agree to stay for a minimum of five years. The position was half-time and the salary $£ 900$ a year. The prospect of reading for the English Fellowship at the age of forty-four must have been a little disturbing. Dunhill, of course, had a Melbourne M.D. and no senior surgical degree. However, Gask finally waived this condition and Dunhill accepted the Assistant Director's post. The idea of the unit system appealed to Dunhill's personality. He thought that this would provide the ultimate in medical and surgical care for the patient. His experience in the war had converted him to the concept of team-work in medicine and its corollary, increasing specialization. Before leaving for London, Dunhill was fêted at a number of dinners held in his honour. His old chief, David Murray Morton, rightly eulogised that Dunhill's work on the thyroid was known to the world and had brought fame on the city of Melbourne, its medical school and on St. Vincent's Hospital. In reply, Dunhill showed a combination of prescience and altruistic innocence. He felt strongly that more specialization in medical practice was needed. He thought that the concept of team-work should be extended to embody a type of nationalization of medicine. He warned that if the medical profession did not lead in this matter, they would ultimately be driven. Finally, he suggested that the Government pay the specialists the same salaries as those of Supreme Court judges!80 Dunhill sailed for England on 5 May 1920.

It may be fairly stated that a prophet is least heeded amongst his own people, and this perhaps applies even more to the medical profession. When Dunhill presented his work on exophthalmic goitre in England in 1912, he was made the subject of thinly veiled attacks directed towards the truthfulness of his claims. Having laid down the guide lines for the treatment of exophthalmic goitre in numerous publications, it is not entirely surprising to read a defamatory article by Stewart McKay* surgeon to the Lewisham Hospital, New South Wales, entitled: 'The role played by the physician and surgeon in the treatment of Graves' Disease'. ${ }^{81}$ In this article McKay repeats the surgical dicta of George Crile in relation to the management of exophthalmic goitre, and then claims to have discovered (or plagiarised) the secret of success. This was a sub-total removal of the thyroid gland, leaving behind the posterior part of each lobe. He then accuses the Melbourne surgeons (meaning Dunhill) of not appreciating this secret in technique. Whilst this modification of the Mikulicz resection was to form the basis of the modern operation for thyroidectomy and at about this time (1920) was slowly being adopted by the Mayo Clinic and Crile, the thyroidectomy performed by Dunhill (removal of one lobe, the isthmus

\footnotetext{
*Stewart McKay (1867-1948). Gifted disciple of Lawson Tait, and surgeon to the Lewisham Hospital in New South Wales for thirty years. Pugnacious and aggressive, he wrote on a multitude of subjects from the behaviour of crayfish to the life of Lawson Tait.
} 

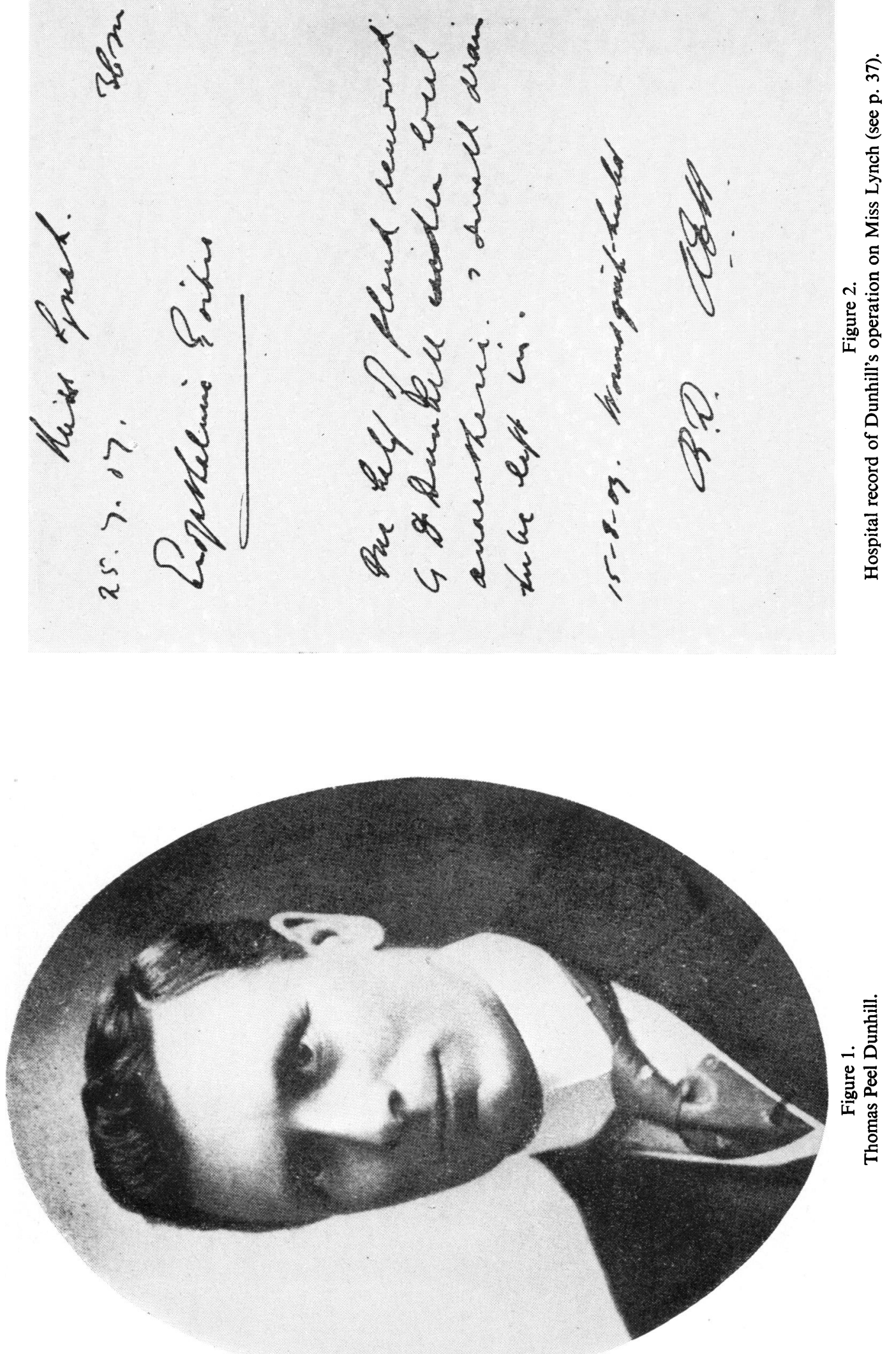


\section{Thomas Peel Dunhill, the Forgotten Man of Thyroid Surgery}

and two-thirds of the other lobe) removed approximately as much tissue and the results were comparable. Dunhill had to work out this technique for himself and had had a vast personal experience with it. His morbidity and mortality rates compared with the lowest in the world and his results were excellent. McKay's experience hardly bore comparison. This article provoked a stinging reply by Frank Davies,* who was Dunhill's anaesthetist for many years. Davies rightly pointed out the envy and petty jealousies which ran through McKay's article. ${ }^{82}$

The Dunhill era would be somewhat incomplete without mention of his classic contribution to the British Journal of Surgery entitled: 'Some considerations on the operation for exophthalmic goitre'. ${ }^{83}$ Aided by a series of magnificent illustrations by A. K. Maxwell, he vividily describes his technique of thyroidectomy whether performed in stages, which he advocates for the very severe case of thyrotoxicosis (one senses that the article was written for the benefit of other surgeons grappling with the problem of exophthalmic goitre), or the one-stage bilateral attack on the thyroid. As mentioned previously, Dunhill differed somewhat from the modern practice of sub-total thyroidectomy by always doing a complete excision of the lobe on one side and excision of the major part of the lobe on the other side. With the second lobe, he left the superior pedicle intact, but of course cut the inferior thyroid artery.

Dunhill's subsequent surgical career at St. Bartholomew's is well known. He obviously had some trepidation at chancing his arm with the London physicians and surgeons and it appears he sounded out the Mother Rectress at St. Vincent's Hospital (Mother Berchmans Daly) as to the possibility of returning to his old post if he failed in London! Subsequent events hardly made that necessary. As Dunhill's career at St. Vincent's came to an end, two other stars commenced to shine in the surgical firmament, namely Hugh Devine and Leo Doyle.** Devine was a contemporary and Doyle the heir apparent of the Dunhill era.

As it is now over sixty years since Dunhill carried out his first thyroidectomy for thyrotoxicosis, some sort of objective assessment of his contributions to thyroid surgery is possible. There is no doubt that in Australasia he alone was responsible for breaking the vicious circle of late patient referral producing high operative mortality, and thereby propagating late patient referral. By his own efforts, he persuaded physicians into realizing the proper role of surgery in thyrotoxicosis. He was the first to champion surgery in the thyrocardiac. He influenced Devine and Doyle in Australia and Joll in England. He was the first to advocate a bilateral attack on the gland in thyrotoxicosis. These achievements should ensure that the name of Dunhill will rightly take its place with Billroth, Kocher, Mayo, Crile and Halsted in the history of the development of thyroid surgery.

\section{ACKNOWLEDGEMENTS}

I would like to thank Professor K. F. Russell of the Department of Anatomy and Medical History, University of Melbourne, for helpful advice and criticism, and Professor R. C. Bennett, Professor of Surgery at St. Vincent's Hospital, for making available the facilities of his department. Both

\footnotetext{
*Frank L. Davies (1878-1962). General practitioner anaesthetist at St. Vincent's Hospital. He gave most of Dunhill's anaesthetics for his abdominal surgery.

**Leo Doyle (1891-1953). Probably one of the most gifted technical surgeons in Australia in his time. An acknowledged master in the use of local anaesthesia, he was equally at home in the thorax or cranium as in the abdomen.
} 


\section{D. A. Vellar}

Dr. Ray Hennessy, consultant ear, nose and throat surgeon and Mr. Leonard Murphy, consultant urologist at St. Vincent's Hospital helped considerably with their continuing encouragement. Mr. R. Grace, Chief Secretary, St. Vincent's Hospital, kindly made available the records of the Hospital and Sister Maureen Walters, Rectress, St. Vincent's Hospital, Melbourne, assisted with the early history of the Sisters of Charity in Australia. I am indebted to the following librarians for their services: Miss E. Binns, Medical Records, St. Vincent's Hospital; Miss A. Bush, Medical Librarian, St. Vincent's Hospital; Miss V. Dunn, Medical Librarian, Royal College of Surgeons of Australasia, Melbourne.

Finally, for their patient collation and typing of the manuscript, I thank Mrs. C. BatesBrownsword, Mrs. K. Broomhall and Miss L. Sangster, all of the University Department of Surgery at St. Vincent's Hospital, Melbourne.

\section{REFERENCES}

1. HALSTED, W. S., 'The operative story of goitre: the author's operation', Johns Hopk. Hosp. Rep., 1920, 19, 71.

2. Liston, R., Lectures on the Operations of Surgery and on Diseases and Accidents Requiring Operations. With numerous additions by Thomas D. Mütter, Philadelphia, 1846, p. 318.

3. Gross, S. D., A System of Surgery, 4th ed., Philadelphia, 1866, p. 394.

4. SICK, P., 'Ueber die totale Exstirpation einer Kropfig Entarten Schilddrüse und über die Rückwirkung dieser Operation auf die Circulations Verhältnisse im Kopfe', Med. Corresp-Blatt Wurttemberg. Arztl. Ver., Stuttgart, 1867, 37, 199.

5. KoCHer, T., 'Zur Pathologie u. Therapie d. Kropfes', Dt. Z. Chir. Leipzig, 1874, 4, 417.

6. Kocher, T., 'Ueber Kropf Extirpation u. ihre Folgen', Arch. klin. Chir. Berlin, 1883, 29, 254.

7. ReVERDIN, J. L., 'Accidents consecutifs a l'ablation totale du goitre', Rev. Med. Suisse, Genève, 1882, 2, 539.

8. GuLl, W. W., 'On a cretinoid state supervening in adult life in women', Trans. clin. Soc. Lond., 1874, 7, 180.

9. Kendall, E. C., 'A method of decomposition of proteins of the thyroid with a description of certain constituents', Collected Papers of the Mayo Clinic, 1914, 6, 352.

10. HoRSLEY, V., 'Note on a possible means of arresting the progress of myxoedema, cachexia strumi priva and allied diseases', Br. med. J., 1890, i, 287.

11. MURRAY, G. R., 'Remarks on the treatment of myxoedema with thyroid juice, with notes of four cases', Br. med. J., 1892, ii, 449.

12. MACKenzIE, H. W. G., 'A case of myxoedema treated with great benefit by feeding with fresh thyroid glands', Br. med. J., 1892, 2, 940.

13. Fox, E. L., 'A case of myxoedema treated by taking extract of thyroid by mouth', Br. med. J., 1892, ii, 941.

14. Mirulicz, J., 'Beitrag für Operationen des Kropfes', Wien med. Wschr., 1886, 36, 1.

15. SANDSTRÖM, L., 'Ueber eine neue Drüse beim Menschen und dei Verschiedenen Saugethieten', Upsala Lak.-Foren. Forh., 1880, 15, 441.

16. Gley, E., 'Sur les effets de l'extirpation du corps thyroide', C.r. Soc. Biol., Paris, 1891, 3,551 .

17. Vassale, G. and Generali, F., 'Sur les effets de l'extirpation des glandes parathyroidiennes', Arch. ital. Biol., Pisa, 1896, $26,61$.

18. MacCallum, W. G., 'The function of the parathyroid glands', J. Amer. med. Ass., 1912, 59, 319.

19. PARRY, C. H., Collected Work, vol. 1, London, Underwood, 1825.

20. Graves, R. J., 'Newly observed affection of the thyroid gland in females', Med. surg. J., $1835,7,516$, pt. 2.

21. Von BASEDOw, C. A., 'Exophthalmos durch Hypertrophie des Zellgemekes in der Augenhöhle', Woch. Ges. Heilkunde, Berlin, 1840.

22. Jaboulay, M., Chirurgie du Grand Sympathetique et du Corps Thyroide, Lyons, 1900.

23. McCarrison, R., The Thyroid Gland in Health and Disease, London, Bailliere, Tindall \& Cox, 1917. 


\section{Thomas Peel Dunhill, the Forgotten Man of Thyroid Surgery}

24. Ibid., p. 200.

25. Kocher, T., Textbook of Operative Surgery, (translated from the 5th German ed. by Harold J. Stiles and C. Balfour Paul), London, Adam \& Charles Black, 1911, p. 447.

26. Ibid., p. 467.

27. GREENFIELD, W. S., 'Some diseases of the thyroid gland', Br. med. J., 1893, ii, 1261.

28. Schultze, K., 'Zur Chirurgie des Morbus Basedow', Mitt. Grenzgeb. Med. Chir., Jena, 1906, 161.

29. Mayo, C. H., 'Goiter, with preliminary report of three hundred operations on the thyroid', J. Amer. med. Ass., 1907, 47, 273.

30. Mayo, C. H., 'Ligation and partial thyroidectomy for hyperthyroidism', Collected Papers by the Staff of St. Mary's Hospital, Mayo Clinic, 1910, p. 476.

31. MaYo, C. H., 'Surgery of the thyroid. Observations on 5,000 operations', J. Amer. med. Ass., 1913, 61, 10.

32. Porter, M. F., 'Injection of boiling water in the treatment of hyperthyroidism', $J$. Amer. med. Ass., 1913, $61,88$.

33. Mayo, C. H., 'The surgical treatment of exophthalmos', J. Amer. med. Ass., 1914, 63, 1147.

34. BALFOUR, D. C., 'The thyroid and a summary of our present knowledge of goitre', Collected Papers of the Mayo Clinic, 1914, 6, 363.

35. MaYo, C. H., 'The principles of thyroid surgery', J. Amer. med. Ass., 1918, 71, 710.

36. JUDD, E. S., 'Results of operations for adenoma with hyperthyroidism and for exophthalmos', Ann. Surg., 1920, 72, 145.

37. Halsted, W. S., 'Practical comments on the use and abuse of cocaine, suggested by its invariably successful employment in more than one thousand minor surgical operations', N.Y. med. J., 1885, 42, 294.

38. Hartley, F., 'Thyroidectomy for exophthalmic coitre', Ann. Surg., 1905, JulyDecember, p. 33.

39. Halsted, W. S. and Evans, H. M., 'The parathyroid glandules: Their blood supply and their preservation in operations upon the thyroid gland', Ann. Surg., 1907, 46. 489.

40. Halsted, W. S., 'Surgical tetany and the parathyroids', J. Amer. med. Ass., 1907, 49, 1243.

41. HALSTED, W. S., 'Report of a dog maintained in good health by a parathyroid autograft approximately one fourth of a millimetre in diameter and comments on the development of the operation for Graves' Disease as influenced by the results of experiments on animals', J. exp. Med., Lancaster, P., 1912, 15, 205.

42. Halsted, W. S., 'The excision of both lobes of the thyroid gland for cure of Graves' Disease', Trans. Amer. surg. Ass., Philadelphia, 1913, 31, 319.

43. Halsted, W. S., 'The significance of the thymus in Graves' Disease', Trans. Amer. surg. Ass., Philadelphia, 1914, 32, 287.

44. CRIIE, G. W., 'Graves' Disease, a new principle of operating, based on a study of 352 operations', J. Amer. med. Ass., 1911, 56, 637.

45. CrIIE, G. W., The Thyroid Gland. Clinics of George W. Crile and Associates, 2nd ed., Philadelphia and London, W. B. Saunders, 1922, p. 221.

46. BERRY, J., 'On the surgery of the thyroid gland with special reference to exophthalmic goitre', Trans. med. Soc. Lond., 1913, 36, 135.

47. MACKenZIE, H. W. G., 'Discussion on partial thyroidectomy under local anaesthesia with special reference to exophthalmic goitre', Proc. roy. Soc. Med., Surgical Section, Part I, 1911-1912, p. 84.

48. Dunlop, J. D., 'Case of myxoedema', Australasian med. Gaz., 1882-1883, 2, 218.

49. FitzGerald, T. N., 'Notes of a case of successful removal of a large goitre', Med. $J$. Aust., 1884, p. 66.

50. FletT, W. S., 'Exophthalmic goitre and its relation to recent discoveries on the importance of the thyroid', Australasian med. Gaz., 1885-1886, 5, 3. 


\section{D. A. Vellar}

51. Lendon, A. A., 'Myxoedema and sporadic cretinism', Australasian med. Gaz., 1894, 13, 152.

52. Martin, A., 'Partial thyroidectomy', Trans. IVth Session Intercolonial Med. Congress of Australasia, Dunedin, New Zealand, 1896, p. 158.

53. Gross, J. O., 'Thyroidectomy in Graves' Disease', ibid., p. 160.

54. GraY, C., 'Notes on a case of exophthalmic goitre. Removal of half the thyroid gland', Intercol. med. J., Australasia, 1898, 7, 280.

55. BIRD, F. D., Review of Diseases of the Thyroid Gland and their Surgical Treatment by James Berry (London, J. \& A. Churchill), Intercol. med. J. Australasia, 1901, 6, 395.

56. Dunhill, T. P. and Patterson, S. W., "Albuminuria following severe exercise in healthy persons', Intercol. med. J. Australasia, 1902, 7, 334.

57. Plummer, H. S. and Boothby, W. M., 'The value of iodine in exophthalmic goitre', Collected Papers of the Mayo Clinic and the Mayo Foundation, 1923, 15, 565.

58. BeEbe, S. P., 'Preparation of a serum for the treatment of exophthalmic goitre', J. Amer. med. Ass., 1906, 46, 484.

59. Barker, A. E., 'Notes on the removal of thyroid tumours', Practitioner, 1907, 79, 331.

60. Jaboulay, M., Chirurgie du Grand Sympathetique et du Corps Thyroide, Lyons, 1900.

61. DunHIIL, T. P., 'Exophthalmic goitre-partial thyroidectomy under local anaesthesia', Intercol. med. J. Australasia, 1907, 12, 569.

62. DuNHIIL, T. P., 'Notes and comments', ibid., p. 589.

63. DunfIIL, T. P., 'Surgical treatment of exophthalmic goitre', ibid., 1908, 13, 293.

64. DuNHIL, T. P., 'Surgical treatment of exophthalmic goitre', Australasian Medical Congress, VIIIth Session, Melbourne, 1908, 1, 365.

65. Ibid., p. 365 .

66. DunhILL, T. P., 'Partial thyroidectomy with special reference to exophthalmic goitre and observations on 113 operations under local anaesthesia', Br. med. J., 1909, i, 1222.

67. Dunhinl, T. P., 'The surgical treatment of Graves' Disease', Med. J. Aust., 1910, $15,625$.

68. HeNNESSY, R., personal communication.

69. DuNHIIL, T. P., 'Partial thyroidectomy under local anaesthesia with special reference to exophthalmic goitre', Proc. roy. Soc. Med., Surgical Section, Part I, 1911-1912, p. 61.

70. DunHIIL, T. P., Lancet, 1912, i, 422.

71. MACKENZIE, H., 'Discussion on partial thyroidectomy under local anaesthesia with special reference to exophthalmic goitre', Proc. roy. Soc. Med., Surgical Section, Part 1, 1911-1912, p. 84.

72. KOCHER, A., ibid., p. 89.

73. BERRY, J., ibid., p. 127.

74. HeNNESSY, R., personal communication.

75. HALSTED, W. S., I., 'The excision of both lobes of the thyroid gland for the cure of Graves' Diseases. II. The preliminary ligation of the thyroid arteries and of the inferior in preference to the superior artery', Ann. Surg., 1913, 58, 178.

76. Balfour, D. C., 'The thyroid and a summary of our present knowledge of goiter', Collected Papers of the Mayo Clinic, 1914, 6, 363.

77. Hinder, H. C., 'The removal of the thyroid gland', Australas. med. Gaz., 1913, 33, 419.

78. Duniml, T. P., 'British Medical Association News', Med. J. Aust., 1916, 1, 492.

79. DunHmL, T. P., 'A discussion on the surgery of exophthalmic goitre', Lancet, 1917, ii, p. 883.

80. DunHIIL, T. P., 'British Medical Association News', Med. J. Aust., 1920, 1, 424.

81. Stewart McKay, W. J., 'The role played by the physician and surgeon in the treatment of Graves' Disease', Med. J. Aust., 1920, 2, 357.

82. DaviES, F. L., 'The Treatment of Exophthalmic Goitre' (Correspondence), Med. J. Aust., 1920, 2, 426.

83. DunfmL, T. P., 'Some considerations on the operations for exophthalmic goitre', Br. J. Surg., 1919-1920, 7, 195. 